\title{
LA OPOSICIÓN Y LOS TRIBUNALES CONSTITUCIONALES
}

\begin{abstract}
Abogado de_la Universidad Nacional Autónoma de México (UNAM). Diplôme d'Etudes Approfondis (DEA) en Instituciones y Doctor en Ciencia Política de la Universidad de Paris I (Panthéon-Sorbonne). Profesor-investigador de la Facultad de Derecho y Administración Pública de la Universidad de Guanajuato, México.
\end{abstract}

\section{RESUMEN}

La protección de la Constitución es un fenómeno sumamente previsible al interior de lassasambleas parlamentarias europeas. La mayoría parlamentaria no actúa de manera tiránica en la medida en que ninguna ley puede ser aprobada atropellando a la minoría política. Tal situación pareció difundirse después de la Segunda Guerra Mundial, a partir del momento en que la fracción minoritaria de un parlamento, podía tener acceso a mecanismos de control de constitucionalidad (especialmente los de tipo "abstracto", en la terminología kelseniana), la oposición "coyuntural" podría estar en situación de reclamar jurídicamente contenidos legislativos que ella misma había sido incapaz de instaurar políticamente (es decir, a través del voto).

La intención del presente artículo, es recorrer a través de la evolución institucional, un tipo de cooperación entre fribunales constitucionales y oposiciones parlamentarias, tal como ha sido representada en lós últimos 50 años en el continente Europeo.

\section{ABSTRACT}

The protection of the Constitution is an extremely foregone phenomenon to the interior of the European parliamentary assemblies. Most parliamentarian doesn't act in a tyrannical way in the measure in that no law can be approved running over to the political minority. Such a situation seemed to spread after the Second World War, starting from the moment in that the minority fraction of a parliament, he/she could have access to mechanisms of control of constitutionality (especially those of type "abstract", in the terminology kelseniana), the opposition "of the situation" it could be in situation of claiming legislative contents that herself had been unable to establish politically legally (that is to say, through the vote).

The intention of the present article is to travel through the institutional evolution, a cooperation type between constitutional tribunals and parliamentary oppositions, just as it has been represented in the last 50 years in the European continent.

\section{PALABRAS CLAVES}

Oposición, Tribunales Constitucionales, Asambleas parlamentarias, Segunda guerra mundial, Gobierno, Jurisprudencia Constitucional, Legislativo, Ejecutivo, Europa continental.

.




\section{KEY WORDS:}

Opposition, Constitutional Tribunals, parliamentary Assemblies, Government, Constitutional Jurisprudence, Legislative, Executive, continental Europe, Majority.

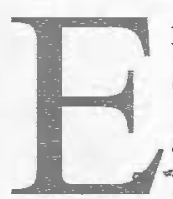

$\mathrm{n}$ " plena mitad del siglo XX, el constitucionalismo de la posguerra, generó un interés por replantear las funciones ejercidas tradicionalmente por las asambleas parlamentarias. La necesidad de reconstruir las instituciones, implicaba un replanteamiento de la función de los parlamentos, éstos últimos como órganos de representación, de creación de normas, de formación del gobierno y de control $^{1}$; y es que en aquél momento, la anquilosada lectura de la independencia orgánica entre gobierno y parlamento, iba a ser dejada atrás a causa de la evolución de la práctica parlamentaria. Ante la demanda de estabilidad institucional, estas asambleas debían enfocarse a garantizar la autonomía funcional de los gobiernos (estos últimos asimilados de ahora en adelante al funcionamiento del gabinete bajo el esquema parlamentario, de tal suerte que éste último hiciera las veces de comisión_ parlamentaria encargada de la administración) ${ }^{2}$.

Después del período de entre-guerras, marcado por el fracaso de constituciones desprovistas de garantías judiciales creadas para proteger a la minoría política (tal como la de la III República francesa o la de la República de Weimar), la ola creadora de nuevas constituciones, después de la Segunda Guerra Mundial, implicaba la redefinición de los postulados del modelo parlamentario. Las adaptaciones al modelo contencioso constitucional (de reciente restablecimiento en la mayoría de los casos) fueron exitosas en tanto atendieron criterios de continuidad, más que de ruptura con el pasado. Fue apenas hace poco, que la transformación de la práctica parlamentaria, ahora marcada por el ideal cooperativo, condujo a exorcizar temores expresados mucho más atrás de los dos lados del Atlántico ${ }^{3}$.

El constitucionalismo de mitad del siglo XX, debía entonces idear la forma en que las cortes constitucionales, mediaran entre la necesidad de promover el espíritu cooperativo propio del parlamentarismo y no impedir el espíritu de competencia política, inherente a los sistemas mayoritarios. Medio siglo después, la tecnicidad de la interpretación constitucional parece ser exportada al ámbito de los órganos políticos a saber (el gobierno y el parlamento) ${ }^{4}$. Hoy por hoy, la jurisprudencia constitucional parece afectar, de forma generalizada, a todos los actores del sistema político ${ }^{5}$.

Después de hacer un recorrido del trayecto protectorconelquelostribunalesconstitucionales

\footnotetext{
${ }^{1}$ La teoría parlamentaria británica del siglo XIX había definido las funciones fundamentales de los parlamentos como las de "bien elegir a los ministros; bien informar a la nación; bien encarnar la voluntad de la nación; bien llevar los asuntos relevantes ante los ojos de la nación", in BAGEHOT, Walter, The english constitution, réimpr. de 1929, New York, Oxford University press (1867), p. 159.

${ }^{2}$ COLLIARD, Jean-Claude. "Les différents modes de gouvernement », Cahiers français, no. 300, janvier-février (2001), pp. 74-80.

3a noción de "tiranía de las mayorías" apareció en TOCQUEVILLE, Alexis, De la démocratie en Amérique (1835), reimpr. de 1963, introducción de H. Laski, Paris, Gallimard, t. I, p. 261-264 ; una primera noción sobre la necesidad de controlar a la mayoría podía encontrarse ya en HAMILTON, Alexander, The federalist papers (1787), reimpr. de 1971, New York, Haskell House Publishers, no. X, pp. 69-77.

${ }^{4}$ WALDRON, Jeremy. "The Integrity of Law: Legislating with Integrity", Fordham Law Review, no. 72, November (2003), p. 373 ss

FLEMING, James E. Congreso del 19 novembre de 2004 "Theories of Taking the Constitution Seriously Outside of the Courts: Judicial Review without Judicial Supremacy", Fordham Law Review, no. 73, March (2005), p. 1377 ss.
} 
europeos han favorecido el establecimiento de grados mínimos de protección para las minorías políticas, podremos apreciar la manera como la esfera de competencias atribuidas a tales jueces parecen cada vez más representadas en el ámbito de la protección de la oposición. Veremos entonces que ésta presencia (concebida también como proceso de juridización de la decisión colectiva) se acentúa considerablemente, cuando el Ejēcutivo o el Legislativo se disponen a tomar decisiones políticas relevantes.

Insistiendo sobre el carácter tan reciente de dicho fenómeno, trataremos de exponer cuáles son los efectos institucionales de la actividad de estos tribunales sobre la oposición parlamentaria. Aunque las democracias europeas contemporáneas se ocupan en muy raras ocasiones de legislar respecto del trabajo parlamentario inherente a la oposición ${ }^{6}$, el carácter tan marginal de ésta protección normativa no representa tampoco un deseo premeditado del legislador. Al menos, visto de los pasados 50 años en Europa continental.

La esencia cooperativa de los sistemas parlamentarios, ha permitido a las instituciones del continente, establecer ligas entre jueces y miembros de minorías políticas; empero, las decisiones colectivas son tomadas, cada vez más, enmarcadas en el binomio de politización/ juridicización. La implantación del espíritu cooperativo en el vértice del parlamentarismo continentaleuropeo, habríasidoimpracticablesin la intervención de los tribunales constitucionales, fue así como la protección de la oposición se fue definiendo como una consecuencia lógica del establecimiento de mecanismos de control de constitucionalidad; dicho de otra forma, el juego de la alternancia lleva al conjunto de los participantes de la dinámica parlamentaria (incluida aquí la mayoría) a interesarse, tarde o temprano, en garantizar los derechos del polo minoritario; en tanto las tensiones entre mayorías y minorías se vieran traducidas en el establecimiento de una relación jurídica, los tribunales encargados de fungir de árbitros en tales conflictos terminarían construyendo una dogmática constitucional coherente a través de cuyos trazos, podrían inclusive pronunciarse y encontrar el justo medio de protección de la oposición parlamentaria.

Al servir de garantía jurídica de la oposición, concluiremos que los tribunales constitucionales europeos han asumido, con cada vez más insistencia, la tarea de catalizadores de la decisión política. ¿Tutelar a la mayoría, o a la oposición? Los teóricos del parlamentarismo mayoritario coinciden en afirmar que, dentro de las condiciones de eficacia de ésta forma de gobierno, la tutela de la oposición es tan importante como lo es la estabilización de la mayoría. Para llegar a este entendimiento, las instituciones debieron transitar por una larga evolución que implicó, al final del camino, que nadie cuestione que ahí donde no hay oposición, no puede haber democracia. En la lógica de los sistemas parlamentarios, la noción de separación de poderes aparece desprovista de sentido cuando su análisis se restringe a entender la liga entre parlamento y gobierno. Esta noción de poder acotado vuelve a encontrar sentido en tanto la liga estudiada se amplía, por un lado, a las tensiones entre la mayoría y el gobierno ${ }^{7}$, así como a las que se generan entre minorías políticas y oposición parlamentaria ${ }^{8}$.

${ }^{6}$ Cf. BADINTER, Robert, Stephen BREYER. Les entretiens de Povence: le juge dans la société contemporaine. Paris: Fayard-Publications de la Sorbonne (2003) 383 p.

${ }_{8}^{7}$ GENNUSA, Maria Elena. La posizione costituzionale dell’opposizione. Milano: Giuffré (2000), pp. 93-137.

${ }^{8}$ Tomando como base uno de los postulados fundamentales del parlamentarismo mayoritario, la función primordial del parlamento no es la de gobernar, pero la de criticar. Por consiguiente, el sentido crítico de esta actividad se dirige, no tanto a modificar las decisiones tomadas por el gobierno, pero más bien a la formación de la opinión electoral (a efecto que ésta última sea quien manifieste la aprobación o desaprobación de la mayoría en turno dentro de las próximas elecciones), JENNINGS, Ivor, Cabinet Governement, Cambridge (1959), pp. 15-16, cit. por BRAZIER, Rodney, Constitutional texts : materials on governement and the Constitution, Oxford, Clarendon Press (1990), pp. 404. 
Nos enfocaremos en seguida, a elaborar un balance de la lectura que la jurisprudencia constitucional europea, ha efectuado en torno a ésta doble relación conflictiva. Este balance nos dará cuenta de la manera como los jueces europeos se dedicaron a disminuir los excesos de la mayoría, extendiendo al mismo tiempo la esfera de protección jurisdiccional a favor de la oposición política.

\section{LA NUEVA OPOSICIÓN EN EL SISTEMA PARLAMENTARIO.}

Las ligas de cooperación que unen a la asamblea legislativa con el gobierno (este último, siendo emanación directa del parlamento) representan el sustrato que conduce a todo parlamento a funcionar eficazmente 9 . Desde el instante mismo en que la mecánica de interacción y de cooperación se colocan como elementos invitados al juego de la negociación política, y en tanto dichas negociaciones permiten que el polo mayoritario sea capaz de tomar decisiones, el sistema normativo debiera garantizar que del mismo modo, "el polo adverso (a saber, la oposición coyunitural ${ }^{10}$ ) actúe bajo la presencia de condiciones mínimas de subsistencia.

Por lo anterior, la protección de las minorías se ha convertido también, en uno de los valores esenciales que orientan el funcionamiento del parlamentarismo; fue sobre todo después de la Segunda Guerra mundial que, la necesidad de armonizar la práctica parlamentaria se dirigió, a hacer coincidir la garantía de los instrumentos procesales de cada fracción de la asamblea con las influencias puntuales que las diferentes minorías pudieran introducir en el proceso legislativo; después de todo, cada uno de estos grupos (aunque de menor importancia) también representaban a un cierto número de electores; pero todavía era necesario en aquél momento generar un debate teórico sobre el significado exacto de la oposición como contrapeso del gobierno. Éste debía entonces acercarse más a la función de un catalizador, y no a la de un elemento que sólo provocara la fragmentación de la representación. En este sentido, la oposición es la minoría que, sin participar del poder, asume que impugna la forma en que éstè está siendo ejercido; pero también existen minorías que no se oponen. En éstos, que han sido llamados regímenes de concordancia, como los Estados Unidos, existen ciertamente divergencias, aunque no exista ninguna oposición de carácter permanente $^{11}$

Bajo los regímenes parlamentarios, el significado de los poderes de control de la oposición se traduce, por una parte, en derechos de información, y por otra, en provocar la dimisión del gobierno en el caso de provocar la ruptura de la liga de confianza; sabemos sin embargo, que la segunda de estas posibilidades implica una carga de tal magnitud, que la puesta en marcha de los mecanismos de responsabilidad política del gobierno (y su logro efectivo) son fenómenos políticos muy poco frecuentes en Europa; por

\footnotetext{
${ }^{9}$ Otro de los postulados centrales de la lógica mayoritaria implica que la oposición deba mantenerse unida (como un bloque organizado) a efecto de permitir que la mayoría recientemente formada funcione de manera diferenciada, pero también, de irse entrenando para asumir el papel de gobierno, llegado el día en que el electorado cambie de opinión y vote mayoritariamente por este bloque. Esto significa que la oposición debe estar siempre preparada para tomar el lugar del gobierno; idem..

${ }^{10}$ LOPEZ AGUILAR, Juan Fernando. Minoría y oposición en el parlamentarismo: una aproximación comparativa, Madrid: Publicaciones del Congreso de los Diputados (1988), pp. 15-22.

${ }^{11}$ El constitucionalismo italiano ha formulađo una distinción entre las minorías eventualesy las minorías tendencialmente permanentes. Pero sólo una clase de minoría se encuentra en situación de acceder al poder al cabo de las siguientes elecciones. Solamente cuando dicha fracción se encuentra desde ese momento representada en el parlamento, y en tanto que ésta ha preparado de antemano un programa alternativo al del gobierno actual, es posible de calificar a esta fracción como oposición coyuntural, PIZZORUSSO, Alessandro, Minoranze e maggioranze, Torino, Einaudi (1993), pp. 43-76.
} 
consiguiente, se ha vuelto sumamente claro que el criterio que permite distinguir jurídicamente a la mayoría de la oposición, ha sufrido un cambio sustancial de especie, que ya no es numérico, sino funcional. La mayoría ya no se define como el grupo más numeroso, sino como el que sostiene al gobierno. Tal criterio parece tan pertinente que es permitida la existencia de gabinetes minoritarios.

Del mismo modo, la oposición ya no se puede definir como minoría, sino como aquél grupo o conjunto de grupos que objetan al gobierno ${ }^{12} . \mathrm{La}$ toma de decisiones en el seno de una asamblea parlamentaria aparece (paradójicamente) más estable en la medida que la oposición pueda presentar abiertamente sus alternativas frente al polo mayoritario. Tal expectativa de la oposición debe ser garantizada incluso en períodos críticos, en los que los actores de la mayoría se han volcado a solicitar la disminución de las diferencias entre fracciones partidistas en beneficio de la unidad naciona ${ }^{13}$.

Siendo una entidad cuyo objeto es la formulación de un programaalternativo, la oposición detenta, cada vez más, mecanismos inștitucionales para defenderse, incluso a posteriori. Tratándose de los sistemas bicamerales, una primera confrontación (política) entre los dos polos de la asamblea debería tener lugar de manera sucesiva, en las dos cámaras del parlamento; las deliberaciones subsecuentes son saldadas en cada Cámara por una votación, aunque este resultado puede todavía ser recusado por vía judicial. Esta expectativa de defensa (transformada en términos contenciosos) tiene que ver con la revisión de la fase política recién concluida; la sustanciación de la misma será entonces efectuada ante la jurisdicción constitucional. La tutela de la minoría implica, en consecuencia, un proceso en el que se incluye tanto a los jueces constitucionales (en la etapa decisoria) como a los parlamentarios (en la etapa del ejercicio de la acción).

\section{LIGAS ENTRE OPOSICIÓN Y JURISPRUDENCIA CONSTITUCIONAL}

Frente al principio parlamentario de protección de la minoría, la evolución del çoncepto de Estado de derecho ha sido garantízada, en gran medida, por la jurisdicción constitucional; el juez ha asumido que al sistema jurídico le concierne establecer condiciones de solidez a la liga de confianza con la institución parlamentaria (ésta última representando el núcleo del sustento de la mayoría). Es así, como asistimos a la construcción de una fuente única de legitimación de la decisión colectiva: la mayoría no tendría razón de ser si no probara su eficacia frente a una oposición sólida.

Para servir como sustento permanente del gobierno, la homogeneidad de la mayoría queda reducida a garantizar que las reglas dirigidas a asegurar el funcionamiento del parlamento no sean debilitadas, pues de lo contrario, el gobierno quedaría expuesto a la amenaza constante del voto de desconfianza en su contra ${ }^{14}$. Sobre este aspecto debemos sin embargo anotar, que la manifestación de la confianza no representa una voluntad inmutable de la asamblea, sino implica una constante negociación entre el gobierno y su

\footnotetext{
${ }_{12}^{12}$ PIMENTEL, Carlos Miguel. «L'opposition, ou le procès symbolique du pouvoir ». Paris: Pouvoirs No. 108 (2003), p. 45. ${ }^{13}$ Id., p. 48.

${ }^{14}$ En Inglaterra, la importancia de la oposición es tal que, incluso durante la Segunda Guerra mundial, la instauración de un Gobierno de Unión Nacional (donde se buscaba alterar lo menos posible la marcha de las instituciones para salvaguardar así el beneficio colectivo) no impidió a que los actores políticos acordaran la subsistencia del "gabinete en la sombra". De forma completamente artificiosa, dos diputados laboristas, nombrados por el Speaker de la Cámara de los comunes, se dieron a la tarea aparente de ejercer dicha función, GUILJ, Sylvie, Le statut de l'opposition en Europe, Paris, La Documentation Française (1980), pp. 30, 49.
} 
propia mayoría, y es que aunque la confianza esté presente en todas las sesiones del parlamento, nada impide al sistema parlamentario a que la dialéctica gobierno/mayoría pueda dar lugar a mutaciones susceptibles de aportar nuevos elementos de juicio a esta posición, pretendidamiente común ${ }^{15}$.

La manifestación de la confianza representa el momento clave, donde se mide el grado de conflictividad dentro del binomio mayoría/ oposición ${ }^{16}$.Esporestoquelaconfrontaciónentre mayoría gobernante y oposición parlamentaria implica la necesidad de establecer mecanismos de compensación. El esquema de separación de poderes se estructura al interior del propio parlamento para establecer con claridad que la mayoría debe mandar, y la oposición, ejercer funciones de crítica y de control del gobierno, pero también de contrapeso de la mayoría (esto último, desde el momento en que actúa como depositaria de garantías constitucionales que corresponden a las minorías de la asamblea). Es en este sentido que el papel de la oposición se transforma en un medio de límites al poder del Estado.

El papel jurídico de la oposición se vuelve incluso más relevante cuando sus funciones son ejercidas para controlar al polo mayoritario, pero la tarea jurídica de los miembros de la oposición no puede ejercerse si no es bajo el formato de una asociación con las jurisdicciones constitucionales. La función de estos tribunales frente a los minoritarios conduce a definir las implicaciones de estos intereses jurídicos (de la oposición) dentro del sistema político.

\section{LA TUTELA DE LAS MINORÍAS, ¿TAREA POLITICA O JURIDICA?}

Como parte del proceso parlamentario, la tutela de los derechos de las minorías se dirige a garantizar condiciones de funcionamiento que reflejen mínimos de igualdad política y de legitimidad democrática; no obstante, órganos distintos a la asamblea participan de tal delimitación de las prácticas parlamentarias. La intervención de estos órganos (como lo es el caso de los Tribunales constitucionales) se presenta de manera subsidiaria: los litigios constitucionales estallan después de que los procedimientos parlamentarios internos fueron agotados. Las democracias europeas han concebido la tutela de las minorías de forma sumamente eficaz y transparente. La constante en estos países consiste en que, para el funcionamiento adecuado de tales mecanismos de protección, se requiere no sólo de la voluntad de la mayoría (en cuanto ésta acepta ła decisión del árbitro), también de la oposición (quien, por el hecho de reclamar razones jurídicas, debe asumirlas y respetarlas el día en que tome el lugar de la mayoría actual).

Algunos constitucionalistas estiman en este sentido que en la medida en que se han transferido atribuciones institucionales a la oposición, el parlamentarismo mayoritario ha logrado volverla políticamente responsable ${ }^{17}$.

Ahora bien, puede afirmarse que ahí donde se plantea una cuestión ante el hemiciclo, se echa a andar la maquinaria protectora de los derechos de los parlamentarios, incluso si no se hubieran formulado pronunciamientos puntuales con carácter definitivo (mismos que serían obligatorios siendo votados por la mayoría), tanto la mayoría como la oposición aceptan quedar sometidos a los efectos jurídicos que emanan de tales mecanismos de protección (en primer lugar parlamentarios; en segundo, jurisdiccionales). Pero la necesidad de estabilizar la acción de los parlamentos (luego, de la mayoría de éstos) implica también el establecimiento de garantías que impidan que la minoría se convierta en un elemento sistemático de bloqueo. Por tal situación, la

\footnotetext{
${ }^{15}$ TOSI, S. Diritto parlamentare, Milano, Giuffré (1974), p. 209.

${ }_{16}^{16}$ LAVAGNA, C. Politica del diritto, no. 2 (1974), pp. 244-246.

17 MANZELLA, Andrea. « Maggioranza ed opposizione in parlamento », in Studi parlamentari e di politica costituzionale, no. 1 (1969), pp. 49-51.
} 
doctrina parlamentaria hace la distinción entre derechos absolutos y relativos de las minorías.

\section{DERECHOS ABSOLUTOS -Y RELATIVOS DE LAS MINORÍAS - -PARLAMENTARIAS.}

Los derechos relativos de las minorías son aquéllos que, como parte de los procesos parlamentarios, condicionan la garantía de la oposición a dejar intocadas las condiciones de estabilidad de la asamblea.

Dentro de los reglamentos parlamentarios, la tutela de las minorías aparece algo disminuida con el propósito de dar solidez a la mayoría (al ser ésta última el sustento directo del gobierno). La puesta en marcha de estas garantías (dichas "de instancia", dentro de las que se encuentra la moción de censura, las funciones de control y de inspección, los controles relativos a la aplicación del reglamento parlamentario $y$, en general, de todo mecanismo que incida en el trabajo parlamentario) quedan entonces encuadradas por filtros impuestos al interior de la propia asamblea. Dentro de esta clase de filtros establecidos constitucionalmente, podemos citar el modelo alemán de "moción de censura constructiva" (art. 67 LF) que condiciona la procedencia de la moción a un acuerdo (por mayoría absoluta) sobre la propuesta de algún candidato que deba suceder al Canciller depuesto. Esta modalidad, reproducida en España (art. $113 \mathrm{CE}$ ) busca evitar que la mayoría sea amenazada por una minoría que no busca más que sacar provecho de la confusión que se deriva de la caída del gobierno actual.

Los reglamentos parlamentarios contemplan mecanismos de estabilización del trabajo parlamentario, tales como la solicitud de sesión a puerta cerrada, la de interrupción del debate o la convocatoria a comisión bicameral (todas estas, susceptibles de ser convocadas por una fracción minoritaria de la asamblea). Frente a estas modalidades que, por conveniencia de ciertas minorías, afirman los derechos de la mayoría, los legisladores europeos han creado garantías absolutas de tutela de la minoría, que repercuten en mejorar la igualdad de oportunidades entre grupos; talès mecanismos reducen los condicionamientos impuestos por la mayoría en el proceso legislativo.

El carácter absoluto de éstos deriva de la necesidad de identificarlos con las tareas propias de la oposición; es así que, al lado de la garantía de organización interna de los grupos parlamentarios, el reconocimiento jurídico de la oposición encuentra reglas de diversas especies dentro de los reglamentos parlamentarios. Las garantías de carácter absoluto inciden en el aspecto estructural de la asamblea, al establecer que las minorías formen parte, por ejemplo, de la Mesa de presidentes del Bundestag. Por virtud del Reglamento de la asamblea, este órgano (llamado Ältestenrat), queda integrado por el presidente, por el vice-presidente de la misma asamblea así como por 23 parlamentarios designados de manera proporcional a sus grupos; es pues empezando por este órgano que, por virtud de las reglas del parlamentarismo, se le otorga un status relevante a la oposición ${ }^{18}$.

\footnotetext{
18 En Francia, el art. 10-II del Reglamento de la Asamblea Nacional estableció ciertas limitantes, a efecto que la Mesa directiva reprodujera, tan fielmente como fuera posible, la composición partidista en el hemiciclo. Esta regla fue admitida también en el Senado (aunque no de forma expresa, sino admitida por la práctica parlamentaria), CARCASSONNE, Guy, « La place de l'opposition : le syndrome français », Pouvoirs, no. 85 (1998), p. 76. Los alemanes, por su parte, se han concentrado en retomar criterios té́ricos y jurisprudenciales a efecto de asimilar la noción de oposición a la de minoría parlamentaria. Los derechos de las minorías son, por consiguiente, entendidos de ambos lados del Rhin como instrumentos que permiten a la oposición conservar un papel propio dentro de la asamblea, volviendo así coercitiva la posibilidad de ejercer controles institucionales.
} 
El aspecto funcional de la asamblea se ve entonces afectado por las garantías de la oposición. Tratándose de comisiones de investigación, los integrantes de éstas (incluso siendo minoritarios) pueden, por iniciativa propia, conyocar audiencias y recibir informes de los comisarios parlamentarios nombrados por el gobierno; pueden también convocar a otros funcionarios de la administración que habrían sido encargados de funciones propuestas por la oposición en el marco de las mismas indagaciones. Finalmente, tal minoría puede, por un porcentaje de un tercio de la asamblea, ejercer un derecho de veto ideado para echar abajo medidas ya admitidas por la mayoría de la asamblea, pudiendo cancelar por este medio la declaración de sesión a puerta cerrada, la abreviación de duración del debate en la primera lectura o incluso la derogación de reglas del Reglamento interior. Algunas de estas garantías de carácter absolute (que aunque no atribuidas a la oposición como tal) pueden ser activadas por cualquier minoría, por poco representativa que esta sea. $Y$ aunque la puesta en marcha de tales garantías sea poco frecuente, éstas podrían ser de mayor utilidad en tanto permiten que un sólo diputado denuncie cuestiones que, habiendo sido discutidas y aprobadas ante la asamblea, no habían sido previstas por el orden del día.

Cabe sin embargo ejemplificar esta modalidad, a efecto de darle significado más aproximado, ya que a primera vista, tales garantías debieran asimilarse a toda regla encaminada a proteger a los parlamentarios en lo individual. En la práctica, esta clase de protección encuentra un sentido únicamente si se le relaciona con alguno de los derechos absolutos precitados; esto significa que rara vez producen efectos por sí mismos.

El objeto de tales mecanismos es el de permitir, que unos cuantos parlamentarios (incluso no inscritos en algún grupo) se encuentren protegidos por los reglamentos respectivos ${ }^{19}$. Pero tampoco puede afirmarse que en este último supuesto, los tribunales invadan la soberanía de los parlamentos cuando se trata de garantizar la posición del polo minoritario a través de procedimientos internos.

Para evitar una consecuencia semejante, el Consejo constitucional francés ha determinado que la evaluación de tipo contencioso deberá quedar circunscrita al momento preciso de presentación del recurso. En este sentido, el juez constitucional de aquél país ha sido cuidadoso en resolver que sólo el Parlamento sería capaz de evaluar elementos procesales previos a la presentación del recurso ${ }^{20}$. Es por esta razón que con mayor frecuencia, tratándose de juicios de incompatibilidad promovidos ante esta instancia, deba ser el parlamento, y no el juez constitucional, quien interviene para asegurar la ejecución de la solución judicial correspondiente $^{21}$. Esta última modalidad que se concentra más en los parlamentarios individuales que en el grupo al que pertenecen, también nos permite afirmar que no todas las garantías de la minoría se traducen en garantías para la oposición, pues en ocasiones, la mayoría y la oposición se ponen de acuerdo para no

${ }^{19}$ En virtud de otras garantías de carácter absoluto, la oposición forma parte (de forma también proporcional) de la Comisión permanente y de las Comisiones de investigación. Tales fracciones minoritarias intervienen igualmente para la determinación de la orden del día; de la definición del tiempo asignado a cada grupo para tomar la palabra en el estrado; en el desarrollo de las lecturas que preceden a la aprobación de una ley así que en las interpelaciones al gobierno. La oposición puede además intervenir en nombre de la minoría dentro de cada una de las Comisiones, formando parte también en las sesiones de preguntas de actualidad al gobierno (cf. los arts. 24, 39, 48, 78, 85, 106 et 116 BTGO).

${ }^{20}$ Estos mecanismos han sido empleados en Alemania para discutir cuestiones como las declaraciones de incompatibilidad de los funcionarios (en el caso de acumulación de mandatos), cuestión que en Francia es más bien resuelta directamente por vía jurisdiccional, ante el Consejo constitucional.

${ }^{21}$ Cf. la decisión no. 77-5-1 DC, relativa a la acumulación de cargos por el diputado Dassault. 
obstruir ciertas iniciativas que convienen a ambas partes, no obstante que en un principio, sólo fueron propuestas por la propia mayoría. Pero no todos los mecanismos de garantía de la oposición se encuentran dentro de las reglas parlamentarias.

Trataremos de demostrar que las tensiones entre mayoría y oposición suelen ser más fáciles de obsefvaăr cuando éstas son llevadas ante órganos ajenos a la asamblea. $\mathrm{Y}$ es que parece que fueron los propios parlamentos quienes asumían no ser los mejores árbitros para resolver conflictos emanados de desequilibrios entre los participantes del debate parlamentario. En tanto el bloque mayoritario en el parlamentarismo continental está interesado en inclinar la balanza siempre de su lado, el orden jurídico estaría interesado en dar a la protección de las minoría un sentido de "legitimar (la postura de la mayoría) a través procedimientos"22.

Con esta afirmación, que bien podría asociarse con la garantía mínima para la oposición, es posible comprender lo importante que es, para el juego democrático, que ésta entidad (minoritaria); del párlamento pueda gozar de garantías, mismas que debieran ser efectivas dentro del hemiciclo, pero también fuera de él, en la fase contenciosa ante los tribunales.

Algunos de los efectos que inciden en el estatuto de la oposición, provienen directamente de postulados de la Constitución (en sentido material). Por esta razón, la eficacia del contencioso constitucional tiene que ver cada vez más con la garantía del desarrollo de la dinámica parlamentaria; esto, no sólo tomando en cuenta a la oposición, al conjunto de los actores, sin importar que éstos pertenezcan a la minoría o a la mayoría.
Si bien es cierto, en materia de protección de la minoría, el contencioso suele iniciarse por virtud de una demanda presentada por la oposición, las repercusiones de estas decisiones judiciales impactan no solamente en la esfera de intereses de estos grupos, sino del sistema político en su conjunto. Es posible que buscando defender el interés (jurídico) de la oposición, los tribunales constitucionales europeos hayan encontrado la circunstancia ideal para introducirse al análisis de las reglas "soberanas" de los Parlamentos. Pero también, fue posible a la oposición utilizar esta vía judicial para difundir la posición ideológica que ésta defendía respecto de ciertos temas.

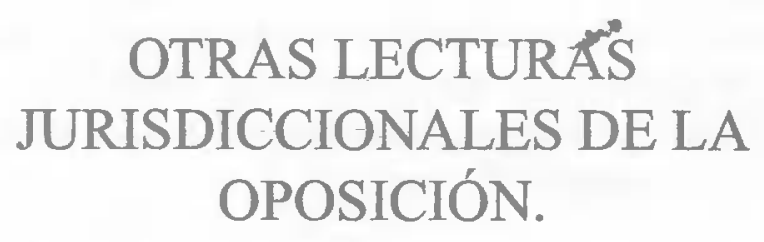

Los instrumentos normativos de que dispone la oposición para desempeñar su función controladora están contenidos, casi siempre, en las reglas del proceso parlamentario. A la luz de la interpretación constitucional, esta esfera de acción no tiene por qué ser disminuida por los jueces; al contrario, la tendencia marcada por estas jurisdicciones durante los últimos años da cuenta de una intención que se dirige a hacer paralelos entre las garantías procesales de la oposición con ciertos principios generales contenidos en la Constitución.

A falta de regla del proceso parlamentario, el juez europeo no duda entonces en atribuir un estatuto preeminente a la oposición. Desde las primeras decisiones del Tribunal constitucional alemán, se determinó que la esencia del sistema parlamentario no puede ser otra que la libre confrontación de opiniones,

\footnotetext{
${ }^{22}$ En el marco de la decisión 1.o. no.2000-294 de 5 de abril de 2000, fueron los órganos del parlamento francés quienes obligaron a renunciar a un diputado que, después del plazo de 30 días concedido en la sentencia, no corrigió la situación que lo hacía incurrir en supuestos de acumulación de mandatos. Ahora bien, estas sentencias, por espectaculares que parezcan, son bastante inhabituales. Sólo siete decisiones de incompatibilidad han sido dictadas en este país desde 1958. BERGOUGNOUS, Georges, Le statut du député, Paris, Assemblée Nationale, série Connaissance de l'Assemblée, no. 7 (2002), pp. 82-85.
} 
aceptando la necesidad de respeto a prácticas institucionales (como la disciplina de partido, de suma relevancia en los parlamentarismos), el juez constitucional determinó que cada parlamentario, en lo individual, no queda ligado permanentemente por el voto que hubiera expresado con anterioridad dentro del hemiciclo. Es perfectamente posible cambiar de opinión en votaciones subsecuentes (ya que no es lo mismo, estratégicamente hablando, votar como mayoría que como oposición). Fallando a favor de la oposición, los jueces de Karlsruhe descartaron la posibilidad de permitir que un registro del comportamiento de un diputado pudiera servir como razón, para el líder de la mayoría, para echar abajo el sentido de un voto que pudo haber demostrado una incoherencia cuando el mismo parlamentario estuvo en el bando contrario ${ }^{23}$.

En otros casos, como lo podría ser el francés, la evolución de las garantías de la oposición fue planeada desde dentro de las mismas instituciones parlamentarias. Nos referimos concretamente as la reforma constitucional de 1974 respecto del artículo $61 \mathrm{CF}$, a partir de la cual, se otorgaba la acción previa de inconstitucionalidad a 60 diputados o a 60 senadores (siendo que, con anterioridad, todas las actuaciones ante este Consejo permanecían restringidas al Presidente de la República, al Primer Ministro o a los Presidentes de ambas Cámaras). Por si fuera poco, los argumentos expuestos en las acciones respectivas serían guardados en secreto hasta 1982, año en que por primera vez, el texto íntegro de las demandas podía ser publicado. Esta última medida había sido establecida por acuerdo de los propios miembros del Consejo constitucional, con la intención de dar mayor claridad a la posición jurídica del polo opositor en el parlamento. Con esto se trataba que ya no sólo el ciudadano común, sino también los simpatizantes o los militantes de partidos opositores pudieran tener elementos para definir sus preferencias electorales. Esta intervención judicial, algo prudente, contrasta con la de otros tribunales (como la del alemán) que definieron el estatuto de la oposición, primeramente, en sentido negativo.

Las garantías de la oposición (en términos del proceso parlamentario) se dirigían con toda claridad a suprimir cualquier interferencia al polo mayoritario. Paralelamente ${ }_{*}$ el Tribunal alemán ordenaba establecer un estatuto de protección de la oposición en sentido positivo, en tanto el carácter participativo de esta entidad minoritaria implicaba necesariamente que la protección a su favor debía ser ejercida de manera completa ${ }^{24}$. De esta forma, se hacía realidad el interés por instaurar no sólo una noción de garantías de la minoría, sino de derechos de una oposición coyuntural. Es por lo anterior que, gracias al juez constitucional, la oposición parlamentaria de este país quedaría encuadrada por una posición jurídica que la reconoce como tal ante el hemiciclo ${ }^{25}$.

En el otro extremo, el modelo francés de protección de la oposición (con un contenido mucho más partidista del contencioso constitucional) desembocó en la posibilidad de acomodar los argumentos de la acción de inconstitucionalidad a cuestiones casi propagandísticas. El demandante tendría que demostrar, como oposición, que estaba siendo coherente con una posición política, sin importar tanto si los argumentos de derecho iban a ser o

\footnotetext{
${ }^{23}$ LUHMANN, Nichlas « Theorie der politischen Opposition », in ZfP (1989), pp. 25-25, cit. por MEZZETTI, Lucca, Giustizia costituzionale e opposizione parlamentare. Modelli europei a confronto, Rimini (1992), p. 79.

${ }_{25}^{24}$ BVerfGE 1, 372 (394) de 29 de julio de 1952 . BVerfGE 1, 372, cit.

${ }^{25}$ MEZZETTI, Lucca, cit. (1992), p. 73.
} 
no tomados en cuenta al final por el tribunal. La construcción de este modelo provocó algunas consecuencias que no dejan de sorprendernos ${ }^{26}$ : En ambos modelos, cualesquiera que sean los motivos que mueven a presentar una acción de inconstitucionalidad, el juez queda circunscrito a la neutralidad del orden jurídico. Lo cierto es que cuando los tribunales constitucionales han tenido que intervenir en aspectos de carácter consuetudinario, la tendencia jurisprudencial instalada hasta la fecha ha sido la de favorecer al polo opositor de la asamblea ${ }^{27}$.

${ }^{26}$ En la decisión relativa a la declaración de conformidad de las leyes bioéticas, la acción previa fue intentada ante el Consejo constitucional por dos ramas distintas de un mismo partido; una (el presidente de la Asamblea Nacional) que defendía la constitucionalidad del proyecto, y otra (62 diputados), que solicitaba su anulación. La ley aprobada concordaba con las intenciones políticas del presidente de la Asamblea (Phillipe Séguin, RPR, partido que en ese momento encabezaba la mayoría). El interés de éste al intentar la acción consistía en demostrar, ante el electorado, que el contenido de la ley no era inconstitucional. Por su parte, una fracción algo conservadora de la misma coalición (RPR-UDF-DL ) pedía la anulación del proyecto. Es así como, en este modelo de protección de las minorías (al tratarse de la "minoría de la mayoría"), la justicia constitucional corre el riesgo de ser utilizada con el único fin de saldar cuentas entre adversarios políticos del mismo partido. Decisión no. 94-343 y 344 DC de 27 de julio de 1994, Recueil de Jurisprudence Constitutionnelle (1994-1997), p. 592.

${ }^{27}$ Así lo estableció el tribunal alemán al evaluar las garantías de los diputados de oposición ante la asamblea (BVerfGE 10, 4 de 14 de julio de 1959). Es posible que, ante la eventualidad que dicho criterio jurisprudencial pudiera ser ampliado en decisiones posteriores, los parlamentarios alemanes instauraron, desde aquella decisión, una nueva práctica parlamentaria que consistió en ampliar la duración de las intervenciones de los líderes de cada grupo parlamentario. Tal tendencia a aumentar la esfera de protección de la oposición se ha registrado con tal claridad, que aunque al principio, el uso de la palabra era distribuido proporcionalmente al número de diputados, actualmente, se ha llegado hasta el establecimiento de una paridad absoluta entre grupos, MEZZETTI, Lucca, cit. (1992), pp. 81-85. 